\title{
Evolution of pore characteristics in oil shale during pyrolysis under convection and conduction heating modes
}

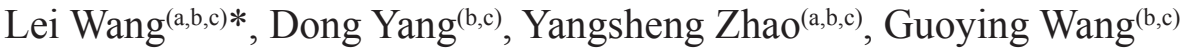

(a) College of Mining Engineering, Taiyuan University of Technology, Taiyuan 030024, P. R. China

(b) Key Laboratory of In-situ Property Improving Mining of Ministry of Education, Taiyuan University of Technology, Taiyuan 030024, P. R. China

(c) The In-situ Steam Injection Branch of State Center for Research and Development of Oil Shale Exploitation, Taiyuan University of Technology, Taiyuan 030024, P. R. China

\begin{abstract}
The pores in oil shale, which act as channels for the migration of products of cracking of organic matter and the place for heat transfer in the rock mass, directly influence pyrolysis efficiency. In this paper, the pore characteristics of oil shale during pyrolysis under the convection and conduction modes of heating were determined by mercury intrusion porosimetry (MIP). Results show that in case of both the heating modes, the threshold temperatures for transformation of pore structure from simple to complex are $382{ }^{\circ} \mathrm{C}$ and $452^{\circ} \mathrm{C}$, respectively. The porosity of oil shale subjected to convection heating is generally higher than that subjected to conduction heating. By the convection heating mode, the high-temperature fluid can extract the shale oil attached to the pore wall and increase the porosity. As the pyrolysis temperature increases from $314^{\circ} \mathrm{C}$ to $555^{\circ} \mathrm{C}$, the average pore size of oil shale increases from 23.70 to $218.15 \mathrm{~nm}$ in convection heating and from 21.68 to $145.60 \mathrm{~nm}$ in conduction heating. During the pyrolysis of organic matter and extraction of oil and gas, high-temperature steam continuously widens the pores. Finally, when the pyrolysis temperature is above $314^{\circ} \mathrm{C}$, pores with a smaller size gradually change into mesopores and macropores with a larger size. It is proved that under the convection heating mode, oil shale changes from a dense rock to a porous medium with an obviously higher amount of pores.
\end{abstract}

Keywords: convection heating, conduction heating, mercury intrusion porosimetry, pore structure, porosity.

* Corresponding author: e-mailLeiwang0327@163.com 


\section{Introduction}

Oil shale is a solid combustible organic mineral with high ash content. Shale oil can be obtained by the retorting process of oil shale, in the course of which, by the thermal cracking of shale oil, products such as gasoline and kerosene are formed. Shale oil is an important strategic material for energy [1,2]. The oil shale resources in China are estimated to be about 720 billion tons, which translates to about 47.6 billion tons of shale oil resources, ranking second in the world.

Oil shale retorting technology is categorized into surface retorting and underground retorting. In case of the former method the oil shale ore, extracted by underground mining, is passed into the surface retorting system for obtaining shale oil and hydrocarbon gas [3]. However, the disadvantages of this technology are high mining costs and an easy collapse of the surface. Moreover, the waste discharge causes environmental pollution. The underground retorting refers to the technology in which the heat injection well is connected to the ore body, so that the oil shale ore can be retorted underground to obtain oil and gas. This technology considers environmental protection as a premise and also brings about an efficient utilization of oil shale. The method applies both modes of heating: conduction and convection $[4,5]$. Irrespective of the type of retorting process, the core concern of oil shale heating and product output is the pore structure development during pyrolysis. Sun et al. [6,7] studied the evolution characteristics of pore structure of Huadian oil shale during pyrolysis. The results showed that the pyrolysis temperature significantly affected the pore structure change of oil shale, while its permeability increased considerably in the temperature range of 350 $450^{\circ} \mathrm{C}$. Han et al. [8] studied the pyrolysis characteristics of Nong'an oil shale by using nitrogen adsorption-desorption and scanning electron microscopy (SEM). The results demonstrated that the proportion of macropores increased with increasing temperature. When the temperature reached $550{ }^{\circ} \mathrm{C}$, the volume of micropores and mesopores increased significantly. Ribas et al. [9] studied the structural changes of oil shale before and after pyrolysis. It was found that these changes were mainly reflected in the rock fabric where fractures parallel to the bedding direction were formed after pyrolysis. Earlier studies mostly focused on the influence of temperature on the microstructure change of oil shale. Analysis shows conduction to have been the main mode of heating oil shale. At the same time, studies on the change of oil shale pore structure under the convection heating mode have been very few.

Zhao et al. [10] developed the technology for the convective heating of oil shale, and Kang et al. [11] elaborated it further. After research, hightemperature water vapor was chosen as heat carrier for heating oil shale.

The pores in oil shale serve not only as channels for the migration of cracking products of organic matter, but also as regions for heat exchange in the rock mass, which directly affects pyrolysis efficiency. Therefore, in the current work, the oil shale pore characteristics, such as porosity, pore size 
distribution and pore structure, at different temperatures of pyrolysis under the convection mode of heating were determined by mercury intrusion porosimetry. The same pore characteristics of oil shale during pyrolysis under the conduction mode of heating were also determined to compare the effect of both heating modes on the process.

\section{Methods}

The oil shale samples used in this study were procured from Barkol in Hami, Xinjiang. In its natural state, oil shale is a dense rock with low permeability. Table 1 summarizes the results of proximate and Fischer assay analyses of oil shale.

Table 1. Proximate and Fischer assay analyses of oil shale

\begin{tabular}{|c|c|c|c|c|c|c|c|c|}
\hline Analysis & \multicolumn{4}{|c|}{ Proximate analysis } & \multicolumn{3}{c|}{ Fischer assay analysis } \\
\hline Composition & $\begin{array}{c}\text { Moisture, } \\
\mathrm{M}_{\mathrm{ad}}\end{array}$ & $\begin{array}{c}\text { Ash, } \\
\mathrm{A}_{\mathrm{d}}\end{array}$ & $\begin{array}{c}\text { Volatile matter, } \\
\mathrm{V}_{\mathrm{d}}\end{array}$ & $\begin{array}{c}\text { Fixed } \\
\text { carbon, } \\
\mathrm{FC}_{\mathrm{d}}\end{array}$ & $\begin{array}{c}\text { Oil } \\
\text { yield, } \\
\mathrm{Tar}_{\text {ad }}\end{array}$ & $\begin{array}{c}\text { Water } \\
\text { yield, } \\
\text { Water }_{\text {ad }}\end{array}$ & $\begin{array}{c}\text { Residue, } \\
\mathrm{CR}_{\text {ad }}\end{array}$ & $\begin{array}{c}\mathrm{Gas} \\
+ \\
\text { loss }\end{array}$ \\
\hline Proportion, \% & 1.36 & 74.82 & 18.48 & 6.70 & 9.25 & 3.12 & 85.58 & 2.05 \\
\hline
\end{tabular}

Note: ad - air dried basis, $\mathrm{d}$ - on dry basis, $\mathrm{CR}$ - coke residue.

The experimental procedure for pyrolysis of oil shale under the convection heating by steam injection is carried out in the reaction system, which consists of a steam generator, a reaction kettle, a temperature monitoring system and a condensation system. The flow rate of steam generated by the steam generator is $3.317 \times 10^{6} \mathrm{~mL} / \mathrm{min}$. The length of the reaction kettle is $4 \mathrm{~m}$, and the thermocouples (T1-T7) are connected at different positions of the reactor, as shown in Figure 1a. In order to carry out the real-time monitoring of the temperature changes in the reaction kettle during the test, the spacing between the thermocouples is set at 600 $\mathrm{mm}$. During the test, firstly, the core of oil shale is withdrawn by a bench drilling machine. Then, the reactor is filled with fragments of oil shale. The predrilled oil shale samples are placed at six temperature measuring points (T1-T3 and T5-T7) and two samples are placed at each measuring point. Finally, after the experiment, the final temperatures at the six measuring points are obtained by the data acquisition system (the final temperatures of T1, T2 and T3 are $555^{\circ} \mathrm{C}, 534{ }^{\circ} \mathrm{C}$ and $511{ }^{\circ} \mathrm{C}$, respectively, whereas those of $\mathrm{T} 5, \mathrm{~T} 6$ and $\mathrm{T} 7$ are respectively $452^{\circ} \mathrm{C}$, $382{ }^{\circ} \mathrm{C}$ and $314{ }^{\circ} \mathrm{C}$ ). No matter the heating mode, two oil shale samples are tested at each pyrolysis temperature by using a Pore Master 33 mercury porosimeter, as shown in Figure 1b. The change of pore parameters with temperature can be established by averaging the pore parameters of two samples. Table 2 gives the average parameters of oil shale samples at different temperatures of pyrolysis under the convection mode of heating. 
(a)

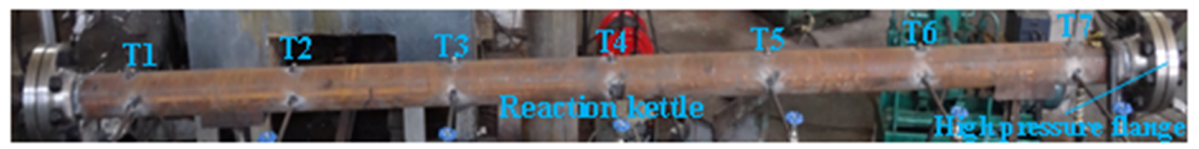

(b)

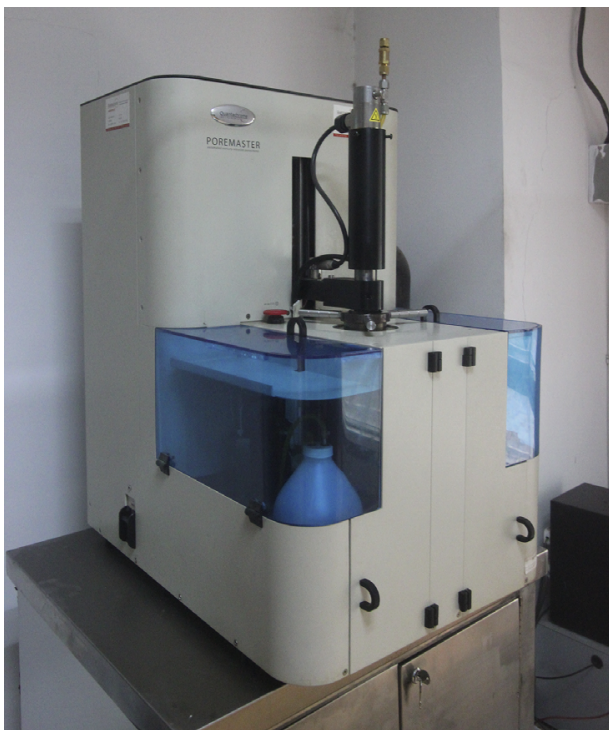

(c)

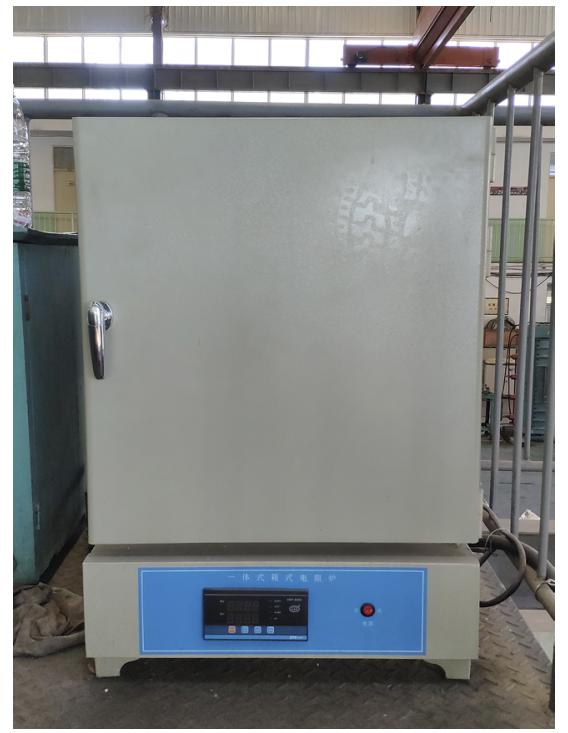

Fig. 1. Schematic diagram of test equipment: a) long airway reactor, b) mercury porosimeter, c) muffle furnace.

Table 2. Average parameters of oil shale samples at different temperatures of pyrolysis under the convection mode of heating

\begin{tabular}{|c|c|c|c|}
\hline \multirow{2}{*}{ Pyrolysis temperature, ${ }^{\circ} \mathrm{C}$} & \multicolumn{3}{|c|}{ Parameter } \\
\cline { 2 - 4 } & Diameter, $\mathrm{mm}$ & Height, $\mathrm{mm}$ & Volume, $\mathrm{mm}^{3}$ \\
\hline 20 & & 7.58 & 503.60 \\
314 & & 6.63 & 440.29 \\
382 & & 7.64 & 507.72 \\
452 & \multirow{4}{*}{9.2} & 7.95 & 528.49 \\
511 & & 8.20 & 545.04 \\
534 & & 8.33 & 553.54 \\
555 & & 9.46 & 628.72 \\
\hline
\end{tabular}


The experimental procedure for recovery of shale oil by oil shale pyrolysis using conduction heat is performed employing an SX2-12-12A muffle furnace, as shown in Figure 1c. The six temperature measuring points are obtained through the above convection heating test. The muffle furnace temperature is set at the same temperatures and the number of samples pyrolyzed at each temperature is 2 . In this experiment, each oil shale sample is tightly wrapped in three aluminum foil layers and then heated. During the process, highly pure nitrogen is introduced into the muffle furnace to ensure that the pyrolysis of oil shale is conducted in an anaerobic environment. The nitrogen flow rate is maintained at $20 \mathrm{~mL} / \mathrm{min}$. Finally, the pore characteristics of oil shale subjected to pyrolysis at different temperatures are determined using mercury intrusion porosimetry. Table 3 presents the average parameters of oil shale samples at different temperatures of pyrolysis under the conduction mode of heating.

Table 3. Average parameters of oil shale samples at different temperatures of pyrolysis under the conduction mode of heating

\begin{tabular}{|c|c|c|c|}
\hline \multirow{2}{*}{ Pyrolysis temperature, ${ }^{\circ} \mathrm{C}$} & \multicolumn{3}{|c|}{ Parameter } \\
\cline { 2 - 4 } & Diameter, $\mathrm{mm}$ & Height, $\mathrm{mm}$ & Volume, $\mathrm{mm}^{3}$ \\
\hline 20 & & 7.58 & 503.60 \\
314 & & 7.55 & 501.66 \\
382 & & 8.26 & 549.14 \\
452 & \multirow{4}{*}{9.2} & 7.74 & 514.49 \\
511 & & 6.18 & 410.57 \\
534 & & 8.16 & 542.08 \\
555 & & 7.76 & 515.78 \\
\hline
\end{tabular}

\section{Pyrolysis characteristics of oil shale under different heating modes}

In Table 4, the average weights of two groups of oil shale samples, before and after pyrolysis, under different heating modes are given. The weight losses of samples are calculated. Figure 2 shows the change in weight loss rate of oil shale with pyrolysis temperature.

It can be seen from Figure 2 that as the pyrolysis temperature increases, the rate of weight loss of oil shale increases. When the pyrolysis temperature reaches $555{ }^{\circ} \mathrm{C}$, the weight loss rates of oil shale under the convection and conduction modes of heating are $16.34 \%$ and $15.94 \%$, respectively. In general, at the same temperature of pyrolysis, the efficiency of convection heating is higher than that of conduction heating. At a temperature of $382{ }^{\circ} \mathrm{C}$, the difference in weight loss rate between oil shale samples pyrolyzed under 
the two heating modes reaches the maximum value, $2.96 \%$. Thereafter, with increasing temperature, the difference in weight loss rate between the samples decreases gradually. The reason for this is that compared to the conduction mode of heating, the heat transfer and efficiency of heat transfer of oil shale under the convection mode of heating are higher. The thermal cracking of oil shale proceeds more intensely and the volatiles in the rock mass are more likely to exude from the fractures formed during this process. At the same time, when organic matter is pyrolyzed vigorously, the high-temperature heatcarrying fluid transports the oil and gas products formed by the decomposition of organic matter to the outside of sample, which improves the active migration ability of oil and gas.

Table 4. Average weight of oil shale samples before and after pyrolysis under different heating modes

\begin{tabular}{|c|c|c|c|c|}
\hline \multirow{2}{*}{$\begin{array}{l}\text { Pyrolysis } \\
\text { temperature, }{ }^{\circ} \mathrm{C}\end{array}$} & \multicolumn{2}{|c|}{ Convection heating } & \multicolumn{2}{|c|}{ Conduction heating } \\
\hline & $\begin{array}{c}\text { Before } \\
\text { pyrolysis, g }\end{array}$ & $\begin{array}{c}\text { After } \\
\text { pyrolysis, } g\end{array}$ & $\begin{array}{c}\text { Before } \\
\text { pyrolysis, } \mathrm{g}\end{array}$ & $\begin{array}{c}\text { After } \\
\text { pyrolysis, } g\end{array}$ \\
\hline 20 & 1.01 & 1.01 & 1.01 & 1.01 \\
\hline 314 & 1.00 & 0.96 & 1.09 & 1.06 \\
\hline 382 & 1.24 & 1.09 & 1.24 & 1.12 \\
\hline 452 & 1.13 & 0.98 & 1.05 & 0.93 \\
\hline 511 & 1.31 & 1.12 & 0.90 & 0.78 \\
\hline 534 & 1.19 & 1.01 & 1.17 & 1.00 \\
\hline 555 & 1.29 & 1.08 & 1.07 & 0.90 \\
\hline
\end{tabular}

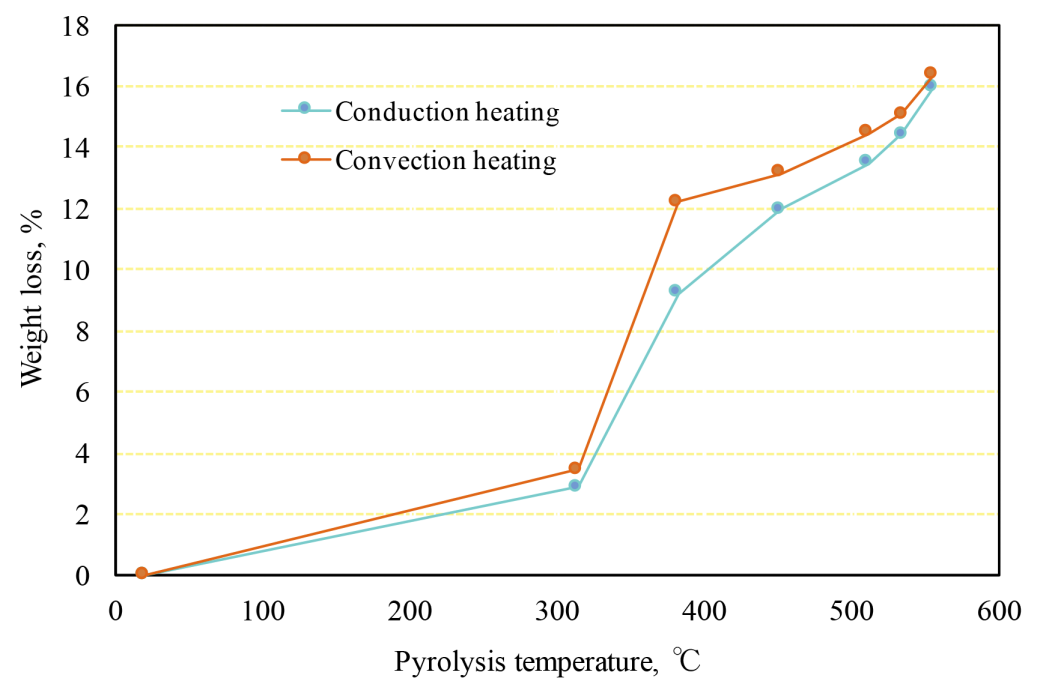

Fig. 2. Curve for weight loss of oil shale against temperature during pyrolysis under different heating modes. 


\section{Pore characteristics of oil shale subjected to pyrolysis under different heating modes}

\subsection{Characterization of pore structure of oil shale}

The pore structure of oil shale is reflected on the shape of mercury injection and withdrawal curves. When the pyrolysis temperature is between $452{ }^{\circ} \mathrm{C}$ and $555{ }^{\circ} \mathrm{C}$, these curves are similar. Therefore, only mercury injection and withdrawal curves obtained below $452^{\circ} \mathrm{C}$ are examined. The mercury injection and withdrawal curves obtained at different temperatures of pyrolysis by convection heating are shown in Figure 3.

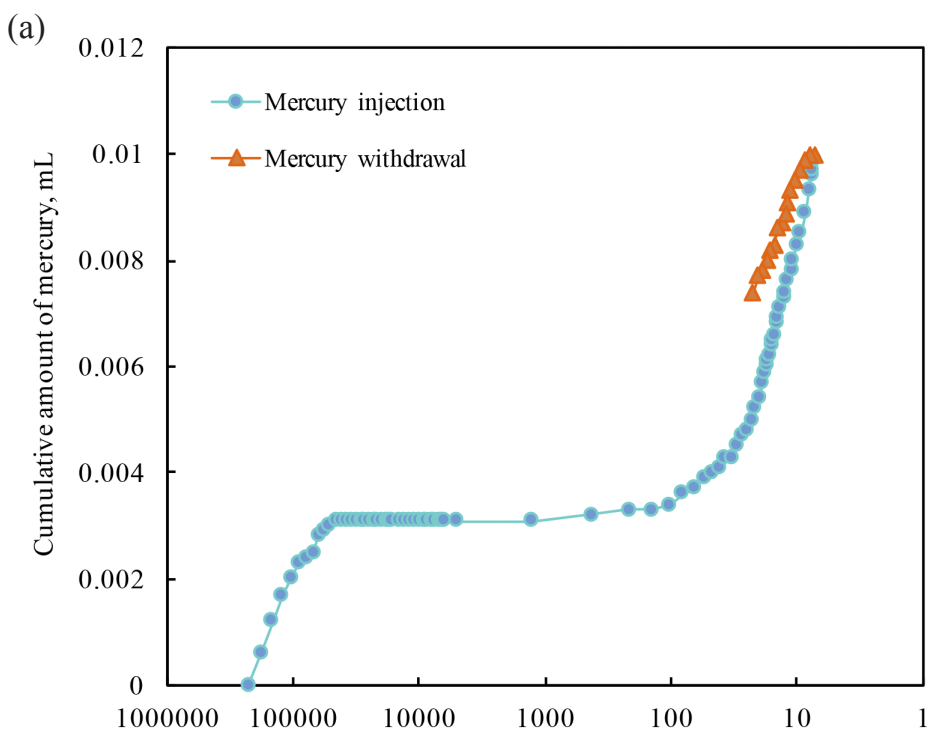

(b)

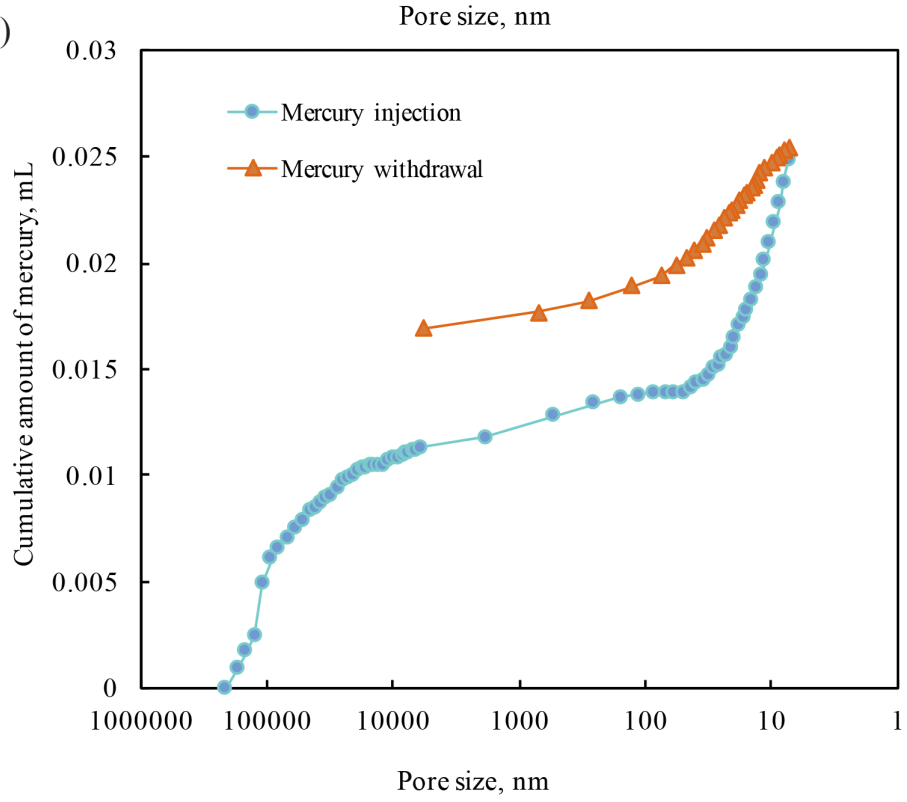


(c)

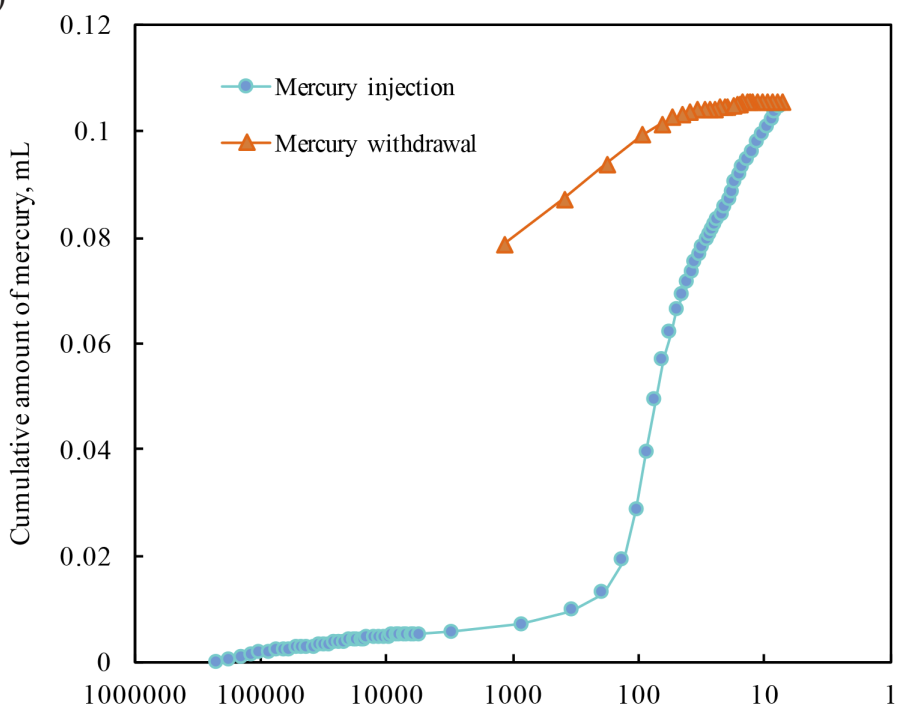

(d)

Pore size, nm

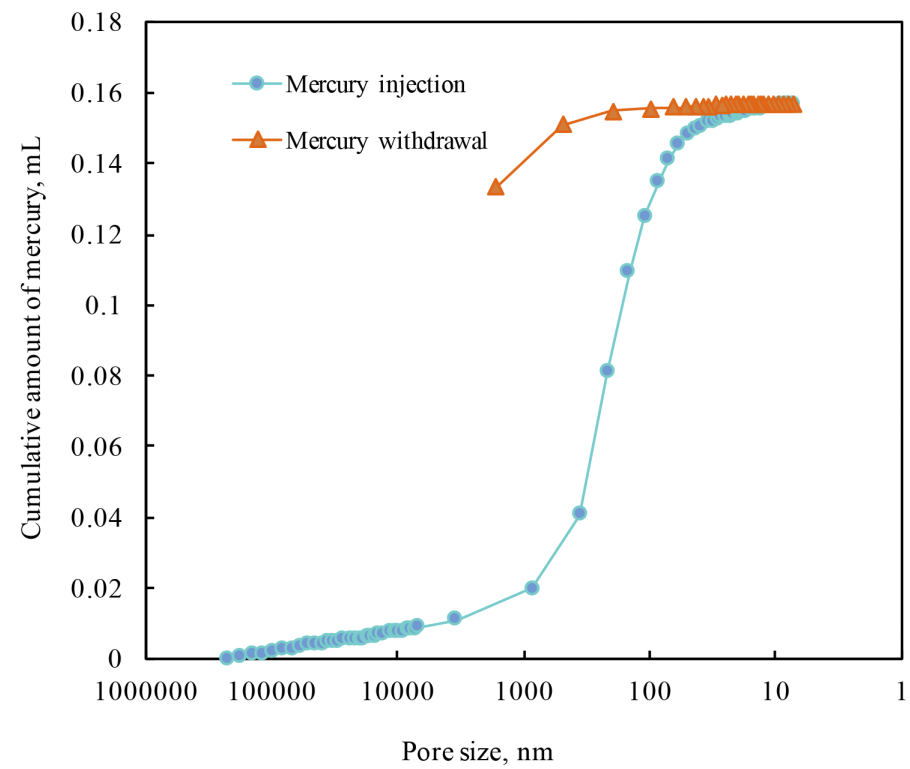

Fig. 3. Mercury injection and withdrawal curves for oil shale pyrolysis at different temperatures by convection heating: a) $20^{\circ} \mathrm{C}$, b) $314{ }^{\circ} \mathrm{C}$, c) $382{ }^{\circ} \mathrm{C}$; d) $452{ }^{\circ} \mathrm{C}$.

At room temperature when the pore size is between 100 and $30000 \mathrm{~nm}$, the cumulative amount of mercury injected remains almost unchanged with changing pore size (Fig. 3a). This indicates that the pores in this pore size range are almost undeveloped. The mercury withdrawal curve is almost parallel to 
the mercury injection curve, which suggests that no mercury remains in the internal pores of the rock mass and hence, no mercury removal is needed.

At a pyrolysis temperature of $314^{\circ} \mathrm{C}$, the cumulative amount of mercury injected increases slowly in the pore size range of 100 to $30000 \mathrm{~nm}$ (Fig. 3b). However, on the whole, the amount of mercury injected is very low and the pore development is still not obvious. At $382{ }^{\circ} \mathrm{C}$, the mercury injection rate changes with changing pore volume (Fig. 3c). With pore size between 344 and $8 \mathrm{~nm}$, the mercury injection rate is higher and this is the main stage of mercury injection. At the same time, the mercury withdrawal curve declines gradually and the efficiency of withdrawal is obvious. Oil shale is a heterogeneous rock. At a temperature of $382{ }^{\circ} \mathrm{C}$, the coefficient of thermal expansion of a hard mineral is quite different from that of adjacent materials, generating a relatively apparent thermal stress in the local area. This leads to the cracking around the hard mineral and an obvious development of pores.

At a pyrolysis temperature of $452{ }^{\circ} \mathrm{C}$, the mercury withdrawal curve is very smooth at the beginning of withdrawal, giving evidence of a noticeable hysteresis phenomenon (Fig. 3d). Some amount of mercury remains in the pores of the complex structure and cannot be removed. Then, the mercury withdrawal efficiency is apparent, indicating that a lot of pores are formed in oil shale above $452^{\circ} \mathrm{C}$. In conclusion, it is evident that $382^{\circ} \mathrm{C}$ is the threshold for the transition of oil shale pore structure from simple to complex. Figure 4 shows the mercury injection and withdrawal curves obtained at different temperatures of pyrolysis by conduction heating.

It can be seen from Figure 4a that at a pyrolysis temperature of $314{ }^{\circ} \mathrm{C}$, the mercury withdrawal curve almost coincides with the mercury injection curve, indicating a simple pore structure of oil shale at this temperature. At $382^{\circ} \mathrm{C}$,

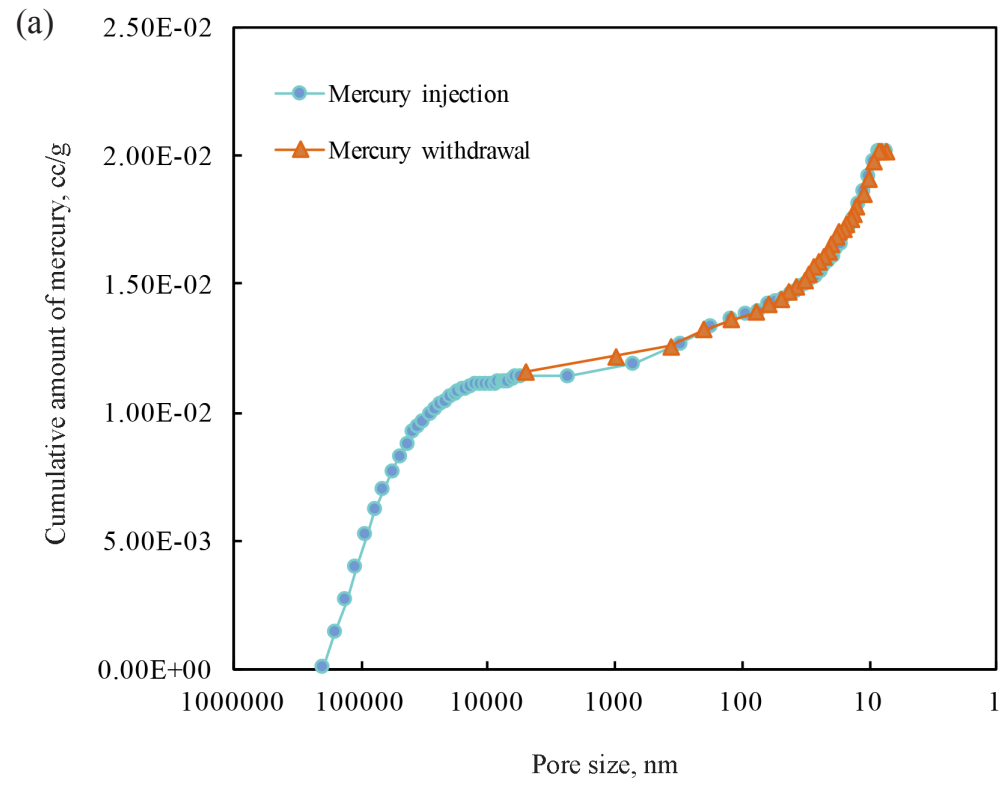


(b)

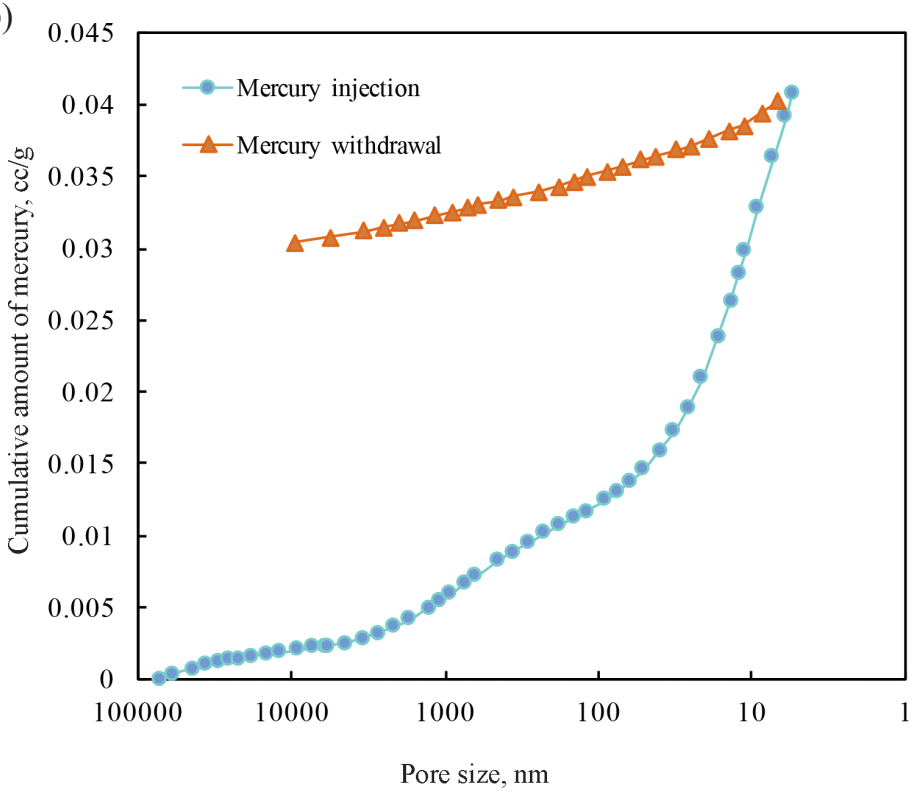

(c)

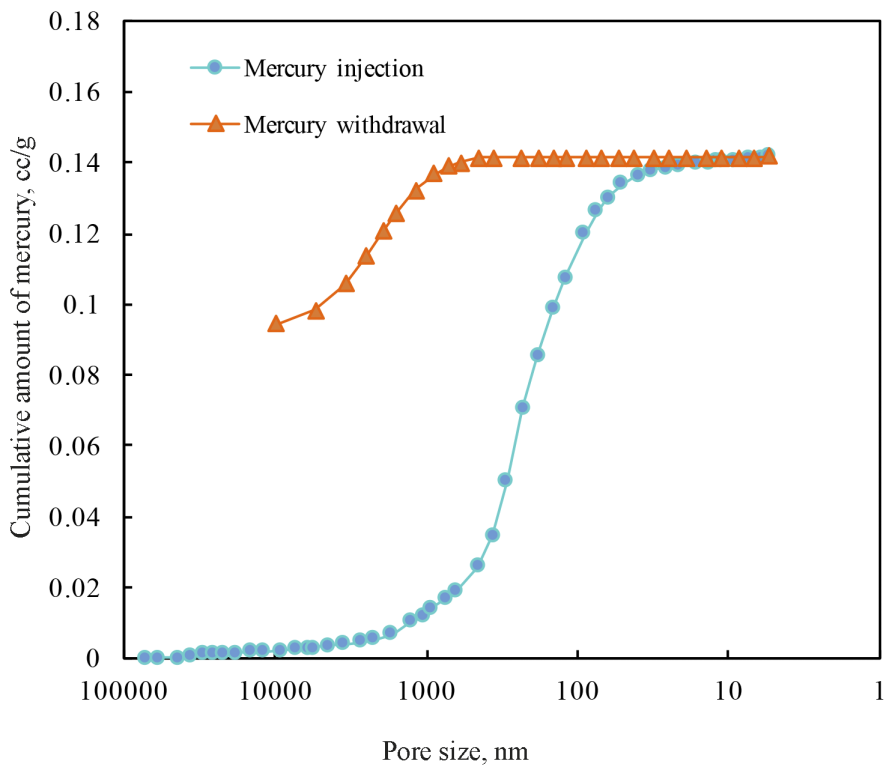

Fig. 4. Mercury injection and withdrawal curves for oil shale pyrolysis at different temperatures by conduction heating: a) $314^{\circ} \mathrm{C}$, b) $382^{\circ} \mathrm{C}$, c) $452{ }^{\circ} \mathrm{C}$.

the mercury withdrawal efficiency is low and the amount of internal pores in oil shale is still small (Fig. 4b). At a temperature of $452^{\circ} \mathrm{C}$, oil shale has many pores and the pore structure is relatively complex (Fig. 4c). This temperature is 
considered to be the threshold for the transition of pore structure from simple to complex in conduction heating.

The above analysis demonstrates that the threshold temperature for oil shale pore structure transformation is lower under the convection mode of heating than under the conduction mode of heating. The reason is that, on the one hand, when the high-temperature steam is used as the heat transfer fluid to pyrolyze oil shale, not only kerogen inside the rock mass undergoes the self-cracking, but also water vapor participates in this reaction, making the pyrolysis process more complicated. On the other hand, when the hightemperature steam carries the pyrolysis products, the oil shale pore channels widen, thereby intensifying the evolution of pore structure.

\subsection{Changes in the porosity and permeability of oil shale}

Porosity is an important indicator for evaluating the extent of pore development in a rock. In the mercury injection test, porosity is the ratio of total pore volume to total medium volume (Table 5) [12]. Permeability is an important parameter reflecting the permeability characteristics of rock mass and can be determined by simulating the flow of fluid through a cylindrical channel [13]. Variations in the porosity and permeability of oil shale with temperature during pyrolysis under different heating modes are shown in Figure 5.

Table 5. Total pore volume of oil shale samples at different pyrolysis temperatures

\begin{tabular}{|l|c|c|c|c|c|c|c|c|}
\hline & \multirow{7}{*}{$\begin{array}{c}\text { Heating } \\
\text { mode }\end{array}$} & \multicolumn{7}{|c|}{ Pyrolysis temperature, ${ }^{\circ} \mathrm{C}$} \\
\cline { 3 - 9 } & & 20 & 314 & 382 & 452 & 511 & 534 & 555 \\
\hline $\begin{array}{c}\text { Convection } \\
\text { heating } \\
\text { volume, } \\
\mathrm{mL}\end{array}$ & 0.0105 & 0.0212 & 0.1135 & 0.1419 & 0.1667 & 0.1556 & 0.2027 \\
\hline $\begin{array}{c}\text { Conduction } \\
\text { heating }\end{array}$ & 0.0105 & 0.0214 & 0.0432 & 0.1164 & 0.1220 & 0.1669 & 0.1447 \\
\hline
\end{tabular}

As the pyrolysis temperature increases from $20^{\circ} \mathrm{C}$ to $314{ }^{\circ} \mathrm{C}$, the increase in the porosity and permeability of oil shale is relatively insignificant under both the heating modes (Fig. 5a, 5b). When the pyrolysis temperature is $314{ }^{\circ} \mathrm{C}$, the oil shale porosity in convection heating is $4.82 \%$ and in conduction heating $4.26 \%$. As $314{ }^{\circ} \mathrm{C}$ is by far not an effective pyrolysis temperature of kerogen, oil shale mainly undergoes thermophysical changes.

When the pyrolysis temperature increases from $314{ }^{\circ} \mathrm{C}$ to $382{ }^{\circ} \mathrm{C}$, the porosity of oil shale increases from 4.82 to $22.36 \%$, which is a 4.64 -fold increase. The permeability increases from 0.53 to $2.61 \mathrm{md}$ in case of the convection mode of heating. Under the conduction mode of heating, the oil shale porosity increases from 4.26 to $7.86 \%$ and permeability from 0.32 to $1.13 \mathrm{md}$. Therefore, when the pyrolysis temperature reaches $382^{\circ} \mathrm{C}$, the porosity of oil 

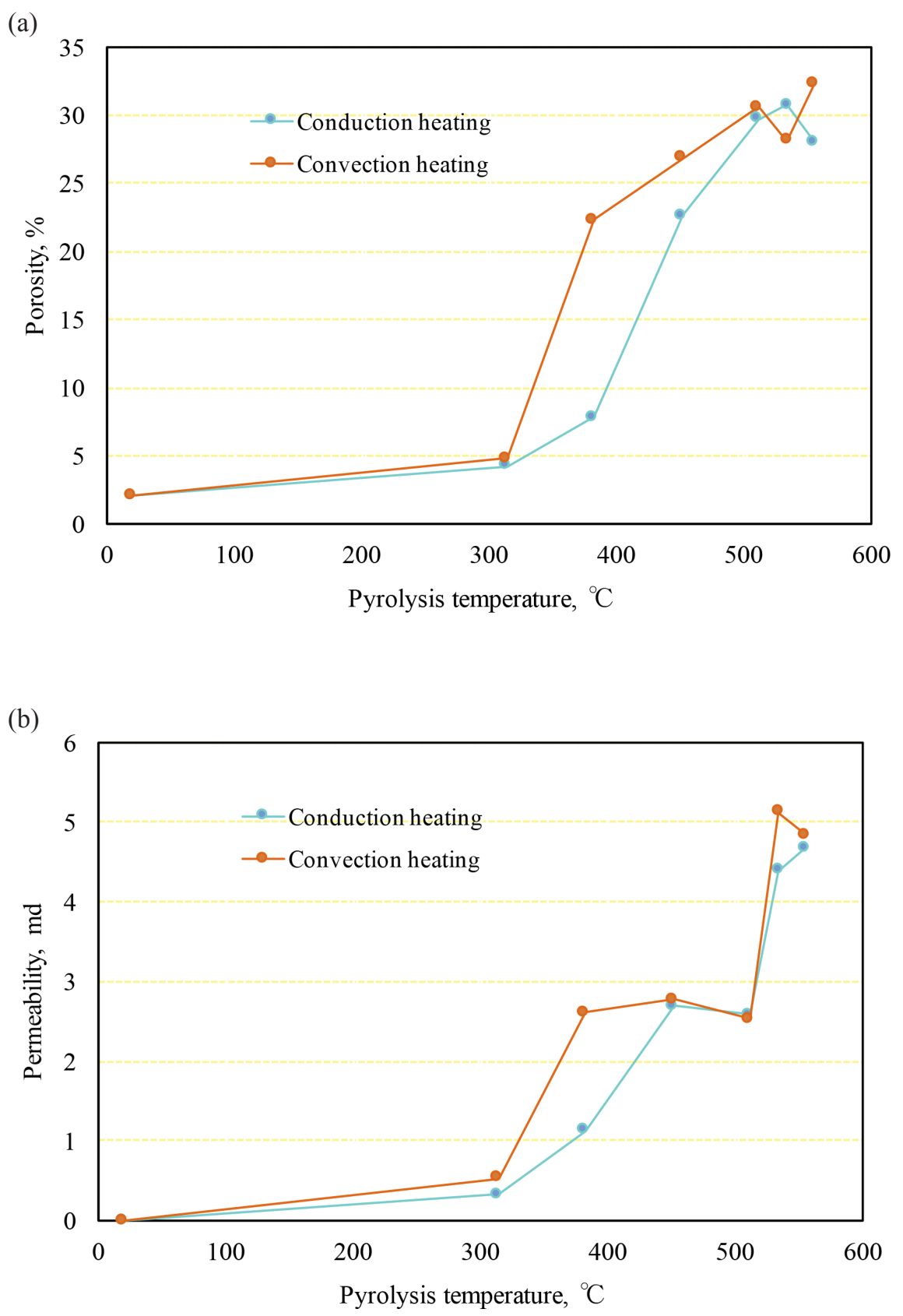

Fig. 5. Variations in the porosity and permeability of oil shale as a function of temperature during pyrolysis under different heating modes: a) porosity vs temperature, b) permeability vs temperature. 
shale heated under the convection mode is much higher than that of oil shale heated under the conduction mode. Oil shale has an obvious bedding structure with low strength. Under the continuous action of superheated steam, oil shale often remains in a three-way tensile state [14], due to which the internal regions of the rock mass undergo a noticeable thermal cracking.

With the pyrolysis temperature increasing from $382{ }^{\circ} \mathrm{C}$ to $555{ }^{\circ} \mathrm{C}$, the porosity and permeability of oil shale increase rapidly under both heating modes. In convection heating, the porosity of oil shale increases from 22.36 to $32.24 \%$ and permeability from 2.61 to $4.84 \mathrm{md}$. In conduction heating, the porosity of oil shale increases from 7.86 to $28.06 \%$ and permeability from 1.13 to $4.68 \mathrm{md}$. At a pyrolysis temperature of $555{ }^{\circ} \mathrm{C}$, the porosity of oil shale under the convection and conduction modes of heating is respectively 15.46 times and 13.46 times that under natural conditions. Organic matter is pyrolyzed at high temperature. During the transformation of kerogen from the solid to gas phase, high expansion stress is accumulated in the pore space, resulting in the formation of numerous pores inside the rock mass under strong pyrolysis conditions.

In general, the porosity and permeability of oil shale by convection heating are higher than those by conduction heating. The reason is that when the pyrolysis temperature reaches the threshold temperature for pyrolysis of organic matter, high-temperature steam can extract the shale oil attached to the pore wall through an extensively fractured structure, thus further increasing the pore space and porosity of oil shale. Moreover, during the precipitation process of high-temperature steam carrying shale gas and shale oil, the pores widen further, forming huge pore spaces and percolation channels.

\subsection{Pore size distribution of oil shale}

Figure 6 illustrates temperature-dependent variations in the average pore size of oil shale pyrolyzed under the conduction and convection modes of heating.

The figure displays that at the same pyrolysis temperature the average pore size of oil shale under the convection heating mode is mostly higher than that under the conduction heating mode. In general, the average pore size of oil shale increases with increasing pyrolysis temperature. When the temperature increases from room temperature to $314{ }^{\circ} \mathrm{C}$, no obvious increase in average pore size is observed in both heating modes. The temperature rise from $314^{\circ} \mathrm{C}$ to $555^{\circ} \mathrm{C}$ increases the average pore size of oil shale from 23.70 to $218.15 \mathrm{~nm}$ by convection heating and from 21.68 to $145.60 \mathrm{~nm}$ by conduction heating. Especially when the pyrolysis temperature reaches $555{ }^{\circ} \mathrm{C}$, the average pore size of oil shale in case of the convection heating mode is much larger than that in the conduction heating mode. This may be explained on the one hand by that the thermal cracking of oil shale becomes more vigorous with steam temperature continuously increasing. The diameter of pores constantly increases during the continuous injection and drainage of high-temperature 


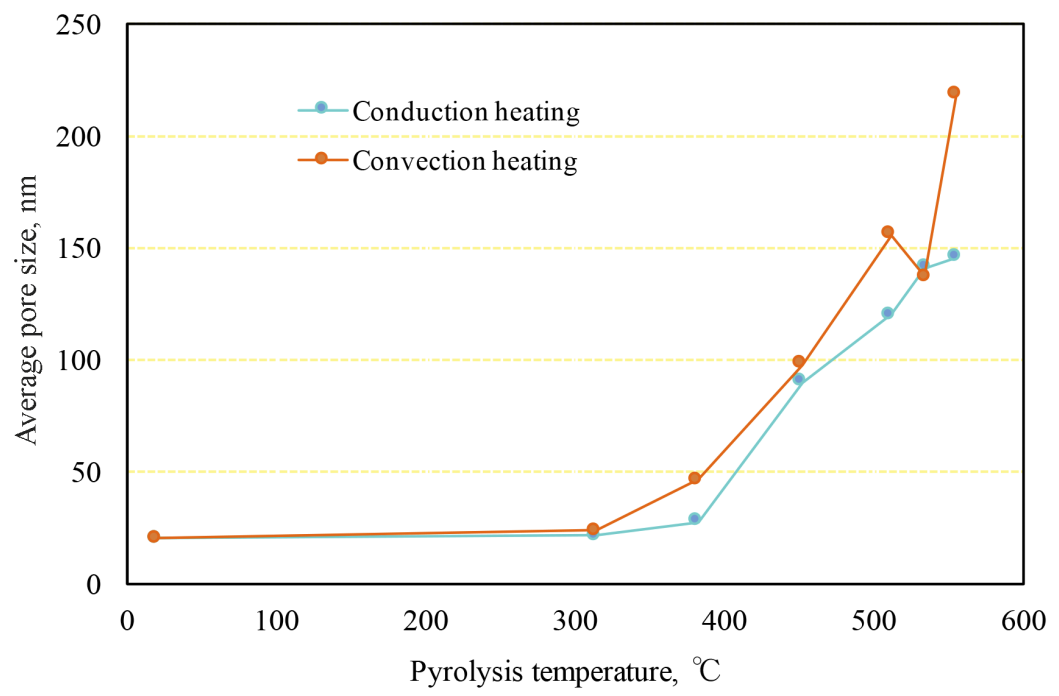

Fig. 6. Variations in the average pore size of oil shale with temperature during pyrolysis under the conduction and convection heating modes.

fluid. On the other hand, the clay minerals present in oil shale undergo slow decomposition at low temperatures. Moreover, the dehydration rate is significant at high temperatures, which accelerates the formation of pores.

\section{Evolution of different types of pores during pyrolysis of oil shale by steam injection}

The above results demonstrate that at the same pyrolysis temperature, the porosity, permeability and pore size of oil shale are higher in the convection heating mode than in the conduction heating mode and the development of pores is more obvious. Therefore, the evolution characteristics of different types of pores during the pyrolysis of oil shale by steam injection are discussed. Based on Hodot's pore classification scheme [15], the internal pores of oil shale can be divided into four categories according to pore size: micropores $(\mathrm{d} \leq 10 \mathrm{~nm})$, minipores $(10 \mathrm{~nm}<\mathrm{d} \leq 100 \mathrm{~nm})$, mesopores $(100 \mathrm{~nm}<\mathrm{d} \leq$ $1000 \mathrm{~nm})$ and macropores $(\mathrm{d}>1000 \mathrm{~nm})$. Table 6 gives the volumes and porosities of different types of pores formed in oil shale during pyrolysis by steam injection. In Figure 7 variations in the porosity of oil shale pores of different size with temperature during pyrolysis by steam injection are shown.

It can be seen from Figure 7 that when the pyrolysis temperature is between $20^{\circ} \mathrm{C}$ and $314^{\circ} \mathrm{C}$, the porosity of all types of pores is very low and oil shale does not undergo a significant thermal cracking at low temperatures. Moreover, the temperature has not reached the threshold for an effective 
Table 6. Volumes and porosities of different types of pores in oil shale pyrolyzed by steam injection

\begin{tabular}{|c|c|c|c|c|c|c|c|c|}
\hline \multirow{2}{*}{$\begin{array}{l}\text { Pyrolysis } \\
\text { tempera- } \\
\text { ture, }{ }^{\circ} \mathrm{C}\end{array}$} & \multicolumn{4}{|c|}{ Pore volume, $\mathrm{ml}$} & \multicolumn{4}{|c|}{ Porosity, \% } \\
\hline & $\begin{array}{c}\text { Mirco- } \\
\text { pores }\end{array}$ & $\begin{array}{l}\text { Mini- } \\
\text { pores }\end{array}$ & $\begin{array}{c}\text { Meso- } \\
\text { pores }\end{array}$ & $\begin{array}{c}\text { Macro- } \\
\text { pores }\end{array}$ & $\begin{array}{l}\text { Mirco- } \\
\text { pores }\end{array}$ & $\begin{array}{l}\text { Mini- } \\
\text { pores }\end{array}$ & $\begin{array}{c}\text { Meso- } \\
\text { pores }\end{array}$ & $\begin{array}{c}\text { Macro- } \\
\text { pores }\end{array}$ \\
\hline 20 & 0.0020 & 0.0051 & 0.0003 & 0.0031 & 0.39 & 1.03 & 0.05 & 0.62 \\
\hline 314 & 0.0036 & 0.0067 & 0.0022 & 0.0087 & 0.83 & 1.56 & 0.47 & 1.96 \\
\hline 382 & 0.0043 & 0.0562 & 0.0453 & 0.0077 & 0.87 & 11.35 & 8.62 & 1.52 \\
\hline 452 & 0.0017 & 0.0322 & 0.0917 & 0.0163 & 0.34 & 6.18 & 17.28 & 3.05 \\
\hline 511 & 0.0008 & 0.0187 & 0.1243 & 0.0229 & 0.14 & 3.48 & 22.82 & 4.15 \\
\hline 534 & 0.0008 & 0.0226 & 0.1167 & 0.0155 & 0.15 & 4.08 & 21.09 & 2.80 \\
\hline 555 & 0.0003 & 0.0212 & 0.1352 & 0.0460 & 0.05 & 3.58 & 21.48 & 7.13 \\
\hline
\end{tabular}

pyrolysis of kerogen. Kerogen undergoes mainly the softening stage, with high viscosity, which blocks some pores. Hence, there is no significant change in pore volume with temperature increasing in this range.

Above $314{ }^{\circ} \mathrm{C}$, the porosity of mesopores and macropores increases with rising temperature. The increase in the porosity of mesopores is more noticeable while that of minipores first increases and then decreases. Some studies have indicated that the threshold temperature for an effective pyrolysis of kerogen is

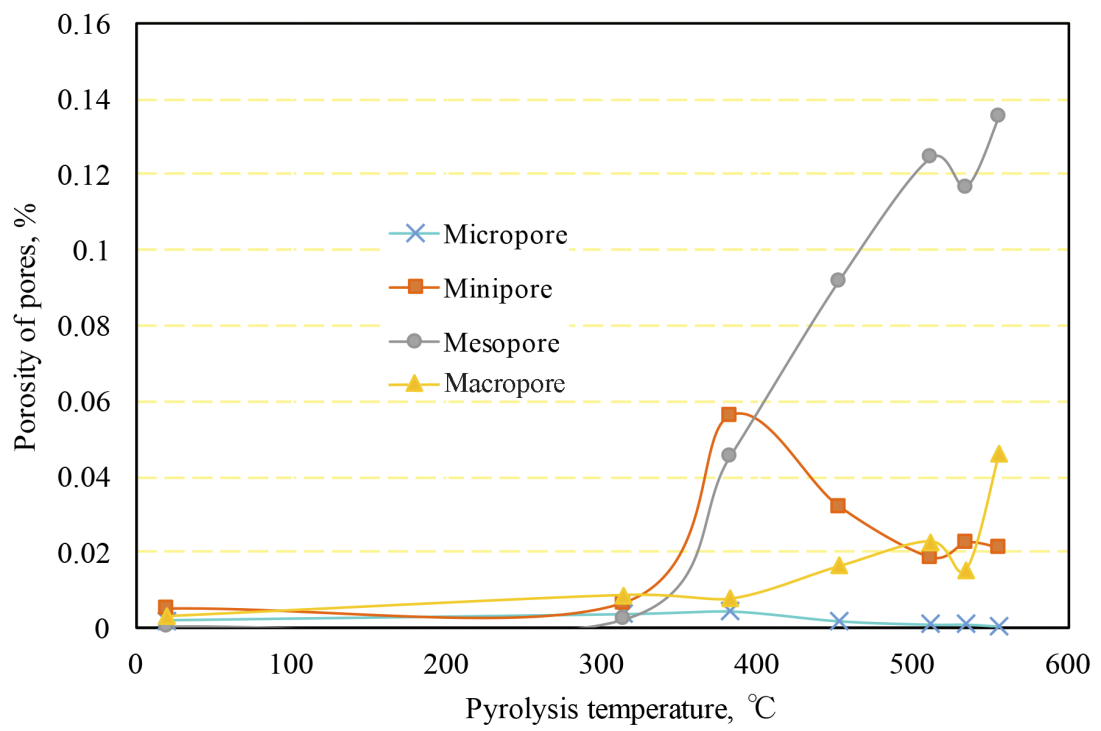

Fig. 7. Variations in the porosity of different types of pores of oil shale pyrolyzed at different temperatures by steam injection. 
$400{ }^{\circ} \mathrm{C}$. After the organic matter begins to effectively decompose, mesopores dominate among the pores, followed by macropores and minipores, while micropores are less abundant. Hence, the order of formation of pores is as follows: mesopores $>$ macropores $\approx$ minipores $>$ micropores.

In summary, when the pyrolysis temperature of oil shale reaches an effective level, the size of internal pores gradually increases. Micropores and minipores with a smaller diameter gradually change into mesopores and macropores with a larger diameter. The main reasons for this are that first, oil shale in the natural state is a dense rock, with few internal pores. During pyrolysis by steam injection, there take place complex chemical reactions of organic matter. These reactions lead to the formation of gas products, due to which the pore diameter gradually increases during the migration process of oil and gas products. Second, in the process of a rapid heat transfer of thermal fluid, the rock mass undergoes obvious physical changes, which are mainly manifested as thermal expansion. Owing to the steam pressure, the pores gradually expand outside the oil shale, which increases the proportion of mesopores and macropores. Third, the strength and hardness of oil shale are relatively high under normal conditions. At high temperature, the deformation of particles with different densities inside the oil shale is chaotic, the strength is greatly reduced and the plasticity is enhanced. Consequently, macro and micro deformation occurs readily under the influence of high-temperature steam.

\section{Conclusions}

In this paper, the evolution of pore characteristics of oil shale during pyrolysis under the convection and conduction heating modes was studied by mercury intrusion porosimetry. The important pore parameters in both the heating modes were calculated. The main conclusions are as follows:

1. The weight loss rate of oil shale in case of the convection heating mode is in general higher than that in the conduction heating mode. Hence, the efficiency of pyrolysis of oil shale in the convection heating mode is higher. The threshold temperature for the transformation of pore structure of oil shale under the convection heating mode is lower than that under the conduction heating mode. By convection heating, oil shale undergoes more complex chemical reactions and physical changes.

2. As the pyrolysis temperature increases from room temperature to $555^{\circ} \mathrm{C}$, the porosity of oil shale increases from 2.09 to $28.06 \%$ in conduction heating and from 2.09 to $32.24 \%$ in convection heating. In the latter heating mode, the high-temperature fluid can extract the shale oil attached to the pore wall, thereby further increasing the pore space and porosity of oil shale. 
3. As the pyrolysis temperature increases from room temperature to $314{ }^{\circ} \mathrm{C}$, the average pore size of oil shale does not increase significantly. With the temperature increasing from $314{ }^{\circ} \mathrm{C}$ to $555^{\circ} \mathrm{C}$, the average pore size of oil shale increases from 23.70 to $218.15 \mathrm{~nm}$ in case of convection heating and from 21.68 to $145.60 \mathrm{~nm}$ in case of conduction heating. In the process of pyrolysis of organic matter and drainage of oil and gas, high-temperature steam continuously increases the pore size.

4. During the pyrolysis of oil shale by steam injection above $314{ }^{\circ} \mathrm{C}$, the volume of mesopores and macropores increases with increasing temperature, whereas that of minipores first increases and then decreases. On the whole, micropores and minipores with a smaller diameter gradually change into mesopores and macropores with a larger diameter.

\section{Acknowledgments}

This work was supported by the National Natural Science Foundation of China (11772213) and the National Key R\&D Program of China (2019YFA0705501).

\section{REFERENCES}

1. Dyni, J. R. Geology and resources of some world oil-shale deposits. Oil Shale, 2003, 20(3), 193-252.

2. Yu, X. D., Luo, Z. F., Li, H. B., Gan, D. Q. Effect of vibration on the separation efficiency of oil shale in a compound dry separator. Fuel, 2018, 214, 242-253.

3. Wang, L., Zhao, Y. S., Yang, D., Kang, Z. Q., Zhao, J. Effect of pyrolysis on oil shale using superheated steam: A case study on the Fushun oil shale, China. Fuel, 2019, 253, 1490-1498.

4. Yang, L. S., Yang, D., Zhao, J., Liu, Z. H., Kang, Z. Q. Changes of oil shale pore structure and permeability at different temperatures. Oil Shale, 2016, 33(2), 101110 .

5. Kang, Z. Q., Zhao, Y. S., Yang, D., Tian, L. J., Li, X. A pilot investigation of pyrolysis from oil and gas extraction from oil shale by in-situ superheated steam injection. J. Petrol. Sci. Eng., 2020, 186, 106785.

6. Sun, Y. H., Bai, F. T., Lü, X. S., Jia, C. X., Wang, Q., Guo, M. G., Li, Q., Guo, W. Kinetic study of Huadian oil shale combustion using a multi-stage parallel reaction model. Energy, 2015, 82, 705-713.

7. Bai, F. T., Sun, Y. H., Liu, Y. M., Guo, M. G. Evaluation of the porous structure of Huadian oil shale during pyrolysis using multiple approaches. Fuel, 2017, 187, $1-8$.

8. Han, J., Sun, Y. H., Guo, W., Li, Q., Deng, S. H. Characterization of pyrolysis of Nong'an oil shale at different temperatures and analysis of pyrolysate. Oil Shale, 2019, 36(2S), 151-170. 
9. Ribas, L., Dos Reis Neto, J. M., França, A. B., Porto Alegre, H. K. The behavior of Irati oil shale before and after the pyrolysis process. J. Petrol. Sci. Eng., 2017, 152,156-164.

10. Zhao, Y. S.,Feng, Z. C., Yang. D.,Liu, S. Y., Sun, K. M.,Zhao, J. Z., Guan, K. W., Duan, K. L. The Method for Mining Oil \& Gas from Oil Shale by Convection Heating. China Invent Patent, CN200510012473, April 20, 2005.

11. Kang, Z. Q., Zhao, Y. S., Yang, D. Physical principle and numerical analysis of oil shale development using in situ conversion process technology. Acta Petrolei Sinica, 2008, 29(4), 592-595 (in Chinese).

12. Chang, Z. B., Chu, M., Zhang, C., Bai, S. X., Lin, H., Ma, L. B. Influence of inherent mineral matrix on the product yield and characterization from Huadian oil shale pyrolysis. J. Anal. Appl. Pyrol., 2018, 130, 269-276.

13. Wang, L., Yang, D., Li, X., Zhao, J., Wang, G.Y., Zhao, Y. S. Macro and meso characteristics of in-situ oil shale pyrolysis using superheated steam. Energies, 2018, 11(9), 2297.

14. Maes, J., Muggeridge, A. H., Jackson, M. D., Quintard, M., Lapene, A. Scaling analysis of the in-situ upgrading of heavy oil and oil shale. Fuel, 2017, 195, 299-313.

15. Geng, Y. D., Liang, W. G., Liu, J., Cao, M. T., Kang, Z. Q. Evolution of pore and fracture structure of oil shale under high temperature and high pressure. Energ. Fuel., 2017, 31(10), 10404-10413.

Presented by S. Li and A. Siirde

Received December 31, 2019 